\title{
Visual analytics to support e-learning
}

\author{
Diego Alonso Gómez Aguilar, Cristóbal Suárez Guerrero, \\ Roberto Therón Sánchez and Francisco García Peñalvo \\ Departamento de Informática y Automática, Universidad de Salamanca \\ Salamanca, Spain
}

\section{Introduction}

The use of visual representations and interaction techniques to provide faster insight into complex data is what distinguishes visual analytics from other types of visualization tools. Visual representations translate data into visible forms that highlight important features, including commonalities and anomalies. These visual representations help users to quickly perceive salient aspects of their data. Augmenting the cognitive reasoning process with perceptual reasoning through visual representations permits the analytical reasoning process to become faster and more focused. Visual Analytics is an emerging area of research and practice that aims to support analytical reasoning through interactive visual interfaces. This chapter discusses important aspects involved in proposing and developing novel interactive visual tool solutions. Those tools can help users of Learning Content Management Systems (LCMS), or Learning Management Systems (LMS) to extract specific knowledge of academic and non-academic information stored in current e-learning platforms. It covers three primary topics. First, it focuses on the psycho-pedagogical theory that justifies the design and use of this software. Next, it addresses the visual representations and interaction techniques and related works that support e-learning. Finally, it considers possible future work and conclusions.

\section{Background}

Information visualization forms part of the direct interface between user and machine.

Visualization is an old term that has received a large amount of interest recently in the computer science community, and will soon be the primary way to interpret the vast amount of data generated by computational science techniques. It has previously been defined as the "formation of visual images; the act or process of interpreting in visual terms or of putting into visual form". More recently a new definition has been added: "A tool or method for interpreting image data fed into a computer and for generating images from complex multi-dimensional data sets" (McCormick et al., 1987).

In data visualization, we graphically represent information utilizing more understandable forms of data and revealing hidden information from contents in VLE. The goal of visualization is to understand the data that can be analyzed and combined with 
visualization to provide a quantitative overview of large and complex data sets, to summarize data, and to assist in identifying regions of interest with appropriate parameters for more focused analysis. A successful visualization can reduce the time it takes to understand the underlying data, to find relationships, and to obtain the information sought. Visual Analytics is an emerging area of research and practice that aims to support analytical reasoning through interactive visual interfaces. It seeks to join together techniques from information visualization with techniques from computational transformation and data analysis.

Visual analytics is a multidisciplinary field that includes the following focus areas: analytical reasoning techniques (it allows users to obtain deep insights that directly support assessment, planning, and decision making); visual representations and interaction techniques (it exploits the human eye's broad bandwidth pathway into the mind to let users see, explore, and understand large amounts of information simultaneously); data representations and transformations (it converts all types of conflicting and dynamic data into ways that support visualization and analysis); and techniques to support the production, presentation, and dissemination of analytical results to communicate information in the appropriate context to a variety of audiences. All of these areas are explained in detail in (James J. Thomas \& Cook, 2005).

On the other hand, E-learning is commonly supported by Learning Content Management Systems (LCMS) or Course Management Systems (CMS). Such Web-based training environments are characterized by the use of very large amounts of information, with strong interactivity and no restrictions on space and time. LCMS and CMS store a log of the students' course activities in a database. They usually have a built-in student monitoring feature that enables the instructor to view certain statistical data, such as the number of accesses made by the student to each resource, a registry of visited pages, the number of logins for each day and so forth. Instructors may use this information to monitor students' activities and to identify potential problems. However, this information is usually provided in a way that poses several problems. For instance, it is highly focused on detail, and it is detached from the course context and/or from the whole e-learning platform of the institution. The information is shown as a text file, or by means of very basic charts. In addition, information of this type has a very simple logical organization that consists of an enormous list of numbers and identifiers. Therefore "one cannot see the wood for the trees" and these platforms tend to offer limited interactivity. As a result, the user becomes frustrated with the very straightforward statistics. Monitoring raw activity data is difficult; one can hardly perceive what is happening, and in many cases the data turn out to be almost incomprehensible. Moreover, the system does not offer knowledge acquisition, nor does it convey any use patterns or highlight specific cases that would require special attention.

Nowadays, the increasing use of new technologies to support learning has fostered the creation of tools that help extract information that is not available at first sight. This is essential for the improvement of the learning process from the point of view of institutional decision makers, educational content providers, teachers, and students, all of whom will benefit from the use of effective analytical tools for current e-learning platforms. The use of visualizations in science learning highlights the potential of multimedia resources; visualizations represent a richer set of resources (extending far beyond text and even static pictures) that can support new learning activities. Opportunities for authentic discovery 
learning is just one example of the ways in which visualizations or other multimedia can provide a learning experience that is fundamentally different from traditional print materials.

E-learning and visual analytics have both experienced growth and obtained excellent results as separate fields of research, yet few efforts have been made to bring the two disciplines into a cooperative setting in order to realize their enormous potential. Moreover, the literature in educational research has established that monitoring student learning is a crucial component of high quality education. Once instructors and students are not in a faceto-face traditional environment, new forms of student monitoring must be explored. The effective use of a CMS requires that instructors be provided with appropriate means of diagnosing problems so that they can take immediate action to prevent or overcome these difficulties.

Following a Visual Analytical approach, the path is to propose and develop innovative interactive visual solutions so as to help different users of e-learning platforms extract specific knowledge related to the complex process of education and learning.

According to (J. J. Thomas \& Cook, 2006), these visualizations and interaction techniques must:

- facilitate understanding of massive and continually growing collections of data of multiple types;

- provide frameworks for analyzing spatial and temporal data; support the understanding of uncertain, incomplete, and often misleading information;

- provide user- and task-adaptable guided representations that enable full situation awareness while supporting development of detailed actions; and

- support multiple levels of data and information abstraction, including the integration of different types of information into a single representation.

\section{Fundamentals of educational psychology}

A significant part of the information necessary for life is obtained through the use of the visual system. Comparing visual perception with the other sensorial systems, it is the primary sensory channel with which the mind constructs its representations. This is true because "it extends the human being beyond his/her own body, is the mediator of other sensory impressions, and acts as a stabilizer between the person and the external world:" (Villalba Simón et al., 2000). Amongst all visual stimuli, those that add the greatest insight to knowledge, and in the shortest period of time, are the graphic-visual representations. This is the reason for their great importance in the learning process.

The function of visual analytic systems in education should encompass not only the exposition of the information, but above all, the transformation of the information into knowledge. Studies about textual representations and graphics as strategies oriented to improving the construction process of mental representations confirms "that the structure of graphics affects the structure of the mental model...," which is why the "learners need opportunities to engage in processing activities in which the demands imposed by the presentation of information are well matched with the individual's capacities to deal with that information."(Ploetzner \& Lowe, 2004).

With this focus, visual analytic systems not only deal with promoting visual learning of the learning content, but also with seeing how the visual component can improve learning 
conditions in and through Virtual Learning Environments, or VLE, where the materials without a doubt play a decisive mediating role. Therefore, the comprehension of this teaching function of visual representations in learning can be understood from sociocultural viewpoints as an instrumental mediation.

According to Vygostky, "all activity depends upon the material with which it operates." (Vygotskii, 2000). From the socio-cultural viewpoint, the presence of instrumental activity interaction with diverse types of physical or symbolic products of culture -is fundamental in learning. It does not deal with an accessory comprehension of the role of instruments in the construction of the mind, but rather, in this conception of the superior psychological processes, development does not exist without the presence of instrumental activity; the learning bears the particular form of the instrument with which the activity is carried out (Suárez, 2008). In the same way that a calculator mediates the activity of a student in solving a math problem, for example, by modifying her way of representing and acting upon the problem to be solved - since the artifact, as the symbolic system that it is, operates as an amplifier of the action - an LMS, as a more complex instrument and environment, suggests a more diverse symbolic system for learning, and thus more elaborate technical and pedagogical attention.

The important factor is to know that the LMS and the different symbolic resources used to learn have a mediating function that transforms, modifies or alters the conditions in which the student learns in the virtual classroom. It is not a matter only of knowing that we can study with visual learning tools, but rather of understanding how these tools can improve the comprehension of the activity in virtual learning. This is a point that justifies the sociocultural theory of the usefulness of LMS as an instrument of socio-cultural mediation. As Bruner states in a synthetic manner, "culture gives form to the mind and provides us with the toolbox through which we construct not only our worlds, but also our conceptions of ourselves and our powers."(Bruner, 1999) .

Therefore, to speak of an image is also to speak of an opportunity of representation, of mediation, of learning activity in the LMS. A visual resource is not a neutral entity; it affects the subject in two ways: as an external action, by allowing the subject to do something (or not) with the support of this resource, and also by affecting the internal representation of the subject: we learn to think with those ways of doing something.

This double orientation is valid when talking about teaching and learning materials in virtual training, when the channel of the educational action is an environment such as an LMS. Therefore, there is a need to understand how these relationships fit in among internal representation, learning, external representation, visual resources, which modes should be used and what types of help should be provided for the students when they learn through visual representation. The main aim is to create useful models that serve to propose better visual conditions for learning (Schnotz, 2002).

Following this constructivist point of view, it is now being increasingly recognized that good learning material in virtual education is that which not only allows the students to reach the proposed objectives, but also facilitates opportunities to learn how to learn (Sangrà, 2008).

Despite the promise of and excitement about visualizations for learning, relatively little is known about how individuals think or learn with visualizations and multimedia. As complex visualizations are increasingly used and made available, more research is possible. But in order for visualizations to be optimally designed and applied in learning situations, 
we must know more about the cognitive processes involved in learning with visualizations. We must also study whether (and how) specific aspects of visualizations impact comprehension processes.

A human being's internal model -cognitive map- is generated based on what we observe. The representation of reality using technology is, in the majority of cases, determinant in accepting and understanding the solution to complex problems. Visualization amplifies human cognitive capabilities (James J. Thomas \& Cook, 2005).

Since 1990 there has been a series of studies examining the effects of diagrams versus text on computer users' performance. There have also been studies investigating the effects of metaphors on learning and information searching. (Butcher \& Kintsch, 2004), compared the effects of visual versus verbal metaphors in facilitating novices and experts in the comprehension and construction of mental models, yielding no significant differences between the visual/verbal metaphor variable or the interaction between metaphor and expertise. The results of the same authors' 2006 study indicate that diagrams have significant effects on the learners' formation of mental models, and that subjects with a high degree of knowledge formed better models. Compared to detailed diagrams, simplified diagrams can better support factual learning. In the second study the protocol analyses showed that simplified diagrams better support information integration, although both types of diagrams can increase comprehension accuracy and facilitate inference generation.

In his research, Butcher (2004) studied the cognitive processes and mental models of learners using visual diagrams in addition to a text. Participants studied with moderately detailed diagrams or text only. The more detailed diagrams emphasized correct structural information about the domain and the less detailed diagrams were simplified to emphasize functional relationships. The presence of diagrams significantly increased the number of inferences produced by participants, but did not influence any other (measured) learning process - monitoring, paraphrasing, or elaboration. In addition, participants who used diagrams demonstrated greater mental model development but the effect was most pronounced for students using the simplified diagrams. The interpretation of these results was that appropriately designed diagrams can successfully promote learning because they successfully guide the learner to engage in cognitive processes essential for comprehension. The design of interactive multimedia e-learning systems is described in (Granda et al., 2008). The research is mainly focused on the design aspects of the shared whiteboard to allow a scalable remote visualization.

Among these materials, the noteworthy mass media include: text, illustrations, animations, audio, video, hypertext, or simulations that offer different degrees of abstraction and concretion. In the case of visual representations, we propose a classification in accordance with their educational function in virtual education.

\section{Visual representations, interaction techniques and related works that support e-learning}

Visual representations can be classified in different ways: by how the visual representation is created (metaphoric, non-metaphoric); by data types (1-, 2-, 3-dimensional data, temporal and multi-dimensional data, and tree and network data) and by in-depth data types (Shneiderman, 1996); by the kind of data represented (temporal, social, hierarchical, etc.); by the design space according to Chi's visualization process steps (Daassi et al., 2006); by time 
dependent data (Muller \& Schumann, 2003); and others. The different types of visual representation, according to their educational function in the learning environment, can have three vectors of use: as a support to represent the learning content, as a learning technique, and as a help to represent the learning process.

\subsection{Visual representation of the learning content or learning objects}

In the first place, the use of visual representation in the educational framework has always been conceived as a didactic resource for presenting learning content. All visual representations - not photographs - of learning content -maps, info graphs, charts, graphics, caricatures, outlines or icons - can receive the name of didactic images or didactic graphics. (Prendes Espinosa, 1994) Their objective is to represent and present the information in an intelligible manner for the student's comprehension. They are distinguished from other types of didactic resources, such as videos, texts or sounds because they use other channels of perception that affect learning in a different way. One of the main functions of visual representations is to promote learning theory for reception.

According to the significant learning theory, "all learning in the classroom can be situated in two independent dimensions: the repetition-significant learning dimension and the reception-discovery dimension." (Ausubel et al., 1983). Therefore, for a learning content - in this case expressed in a visual representation - to be relevant in learning, it should be both stable - unitary and congruent in itself - and functional - adjusting to the demands of the specific task - but, above all, it should ensure other conditions as well: first, regarding the learning content (the validity of the information, the internal organization of the content, the sequence of the presentation, the chromatic design, etc.), and second, with respect to the student (the learning content is adjusted to their previous understanding, their motivations, the educational level, etc.).

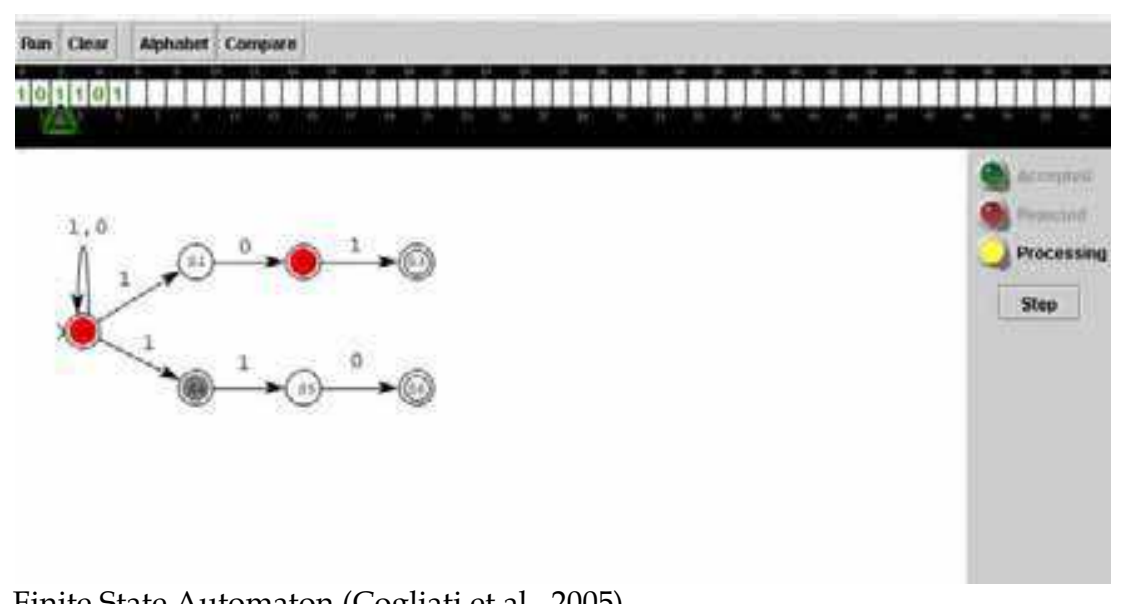

Fig. 1. Finite State Automaton (Cogliati et al., 2005).

Not all learning help is visual, just as neither does it all have the same characteristics. If it is assumed that all language possesses different systems of significance, visual representations are given by a series of codes that are their own and are exclusive to visual language 
Therefore, the interpretation that the student makes of the didactic image is not an exclusively sensorial phenomenon; rather, it is interpretative because it transfers information that is different from textual or oral information.

Visual usage has an important place accompanying oral exposition or clarifying written text. The function of these visual representations of the curricular content, the didactic image, is to facilitate students' learning by integrating information, exhibiting abstract concepts, organizing complex information, or guiding the solution of problems. They should be more elaborate when learned in an LMS.

Colgliati et al. (2005) presented a visualization system to produce comprehensive resources for supporting an entire course or course module on the theory of computing. Fig. 1 represents a snapshot of the exercise version of the finite state automaton and an active learning model is shown. Colgliati et al. at times refer to the kinds of active learning applets above as active learning models, since the concepts visualized by them are models (e.g., of finite state automata, regular grammars). They also designed different types of active learning applets to support other aspects of teaching and learning, and at times refer to these applets as active learning tools; among them are the following: a slide show presentation system, a video clip display module, and a program animator.

Another group of works deals with the use of visualization, rather than information analysis, as part of the learning process or as a supportive resource for coursework (Robling et al., 2006) and formulates a vision of how various aspects are important in the process of developing visualization.

As regards the traditional way of using visual representation in learning, a lot of the effort in virtual training has been put into improving materials by promoting Learning Objects (LO). An LO is defined as "A digital self-contained and reusable entity, with a clear educational purpose, with at least three internal and editable components: content, learning activities and elements of context. The learning objects must have an external structure of information to facilitate their identification, storage and retrieval: the metadata" (Chiappe et al., 2007). These digital pieces, as learning materials, are constant in the virtual education field, visually representing the learning content.

Interactive Classroom Visualizations (ICV) can be an effective means to promote active learning in the classroom. They should be designed with characteristics similar to other active learning exercises. If they are used correctly in the classroom, they can result in educational benefits similar to those of other active learning activities. Some common characteristics of such activities are: interactivity, simple to understand, short time frame, creative and motivational, sometimes collaborative, relevance (Schweitzer \& Brown, 2007).

Chudá (2007) presents the use of a Learning Object (LO) to help undergraduate students to understand the concepts of Automata theory. The article also explains the benefits of reusable LO, based on a standard structure and/or adopting a schedule of their maintenance.

Interest is the incentive and motive for study. To promote this interest, Ariyasu (2005) proposed a procedure for automatically adding stage directions to dialog text based on who is speaking and what they are saying, thereby turning the discussions into a combination of images and sound that learners found more interesting. They have also built a virtual classroom system using 3D CG (computer graphics). Fig. 2 shows a screenshot of the virtual classroom, which consists of a computer-generated set in which the learners participating in a discussion are displayed as avatars. Statements made by the learners are transferred in 
real time as text data and depicted in video form as the utterances of the avatars appearing in the virtual classroom.

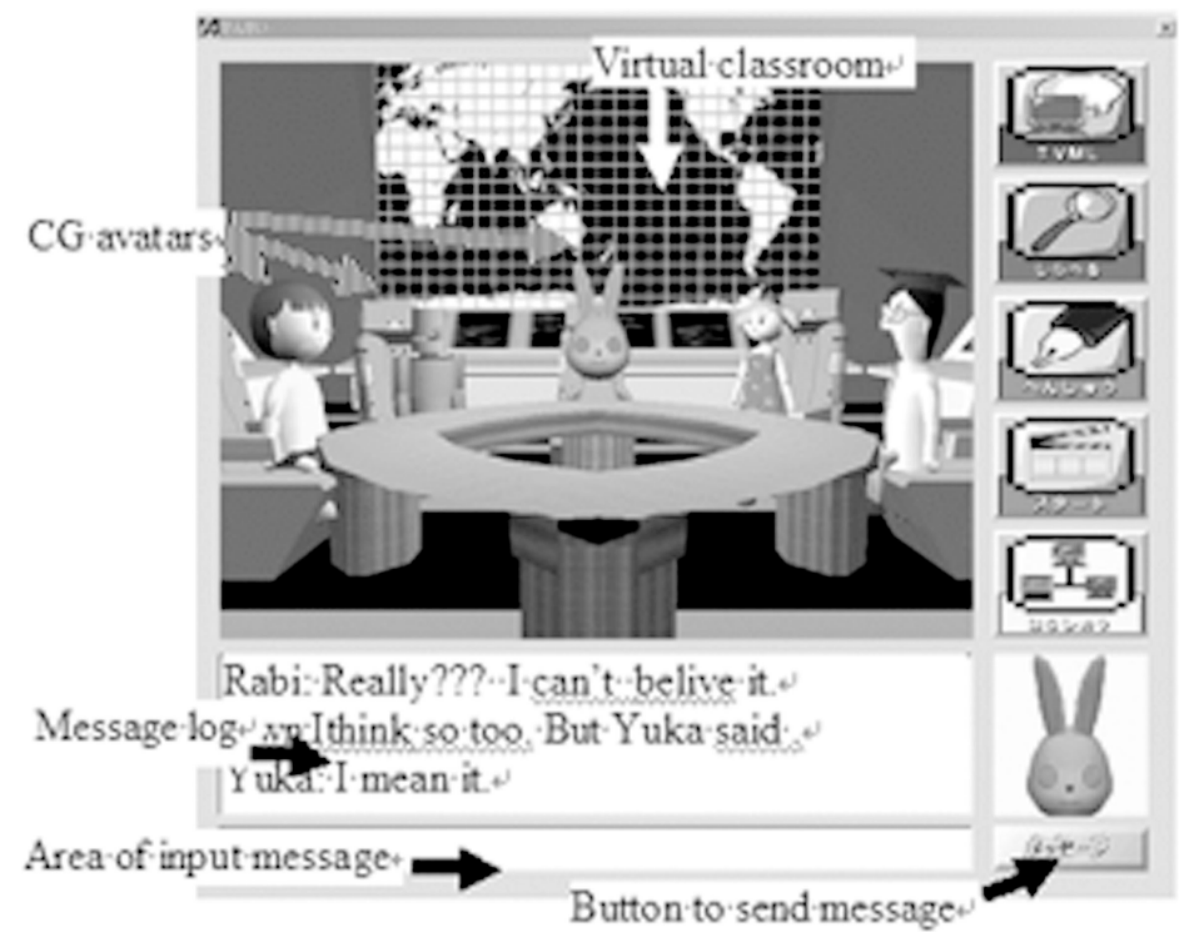

Fig. 2. Example of virtual classroom screen (Ariyasu et al., 2005).

Due to limited space, some experiences in the literature that deal with the analysis of information generated by LMS through visual representations are listed and briefly explained below.

\subsection{Visual representations as a learning strategy to organize and manage learning objects or concepts}

Besides representing the learning content of teaching, the visual representations are also used as learning techniques under the name of Graphic Organizers (Ewy, 2003). The goal of these visual tools is to enable the students themselves to organize the content graphically, thereby making learning more efficient as well as increasing students' motivational factors. Among its advantages, the following elements can be highlighted: its value in representing complex information, processing information, identifying connections between concepts, identifying conceptualization errors, organizing hierarchy or inclusion relationships, and improving the personal comprehension of learning.

However, for these Visual Organizers to have a positive effect on learning, it is not enough to simply apply them; teachers as well as students must understand their main characteristics, and additionally be aware of the learning objective for which their use is 
intended. Therefore, a teacher with experience in this area is needed to propose them, given that each Graphic Organizer proposes the information representation in a different form, and a certain student competence to visually process and organize the information is required as well in order for the student to achieve the best outcome.

A great variety of Graphic Organizers exists, such as conceptual maps (useful to organize and represent the relationships of the conceptual hierarchy visually), idea maps (useful to promote brainstorming, devise plans of action and analyze problems), spider webs (useful for connecting the secondary information to the central information), cause-effect diagrams (useful for recognizing causal relationships between two or more phenomena, facts or concepts), timelines (useful for setting up sequences of events or milestones in a temporal way), organization charts (useful in organizing the functional relationships in a hierarchy), cyclic graphics (useful to represent a sequence of events which is repeated periodically), flow diagrams (useful to represent schematically the sequence of an algorithm instruction or the steps of a process), Venn diagrams (useful to establish different ways in which sets can be related), among others. All this is aimed at getting the students to represent the information graphically, thereby facilitating their learning.

Given their usefulness, there exists a line of work and research in education that supports the use of these Graphic Organizers in different educational experiences and that has been extended thanks to the computer advances in virtual education (Software, 2003). Today, the use of web tools is being strengthened to create these graphic organizers and help students with the construction of their knowledge models (Castaño, 2004).

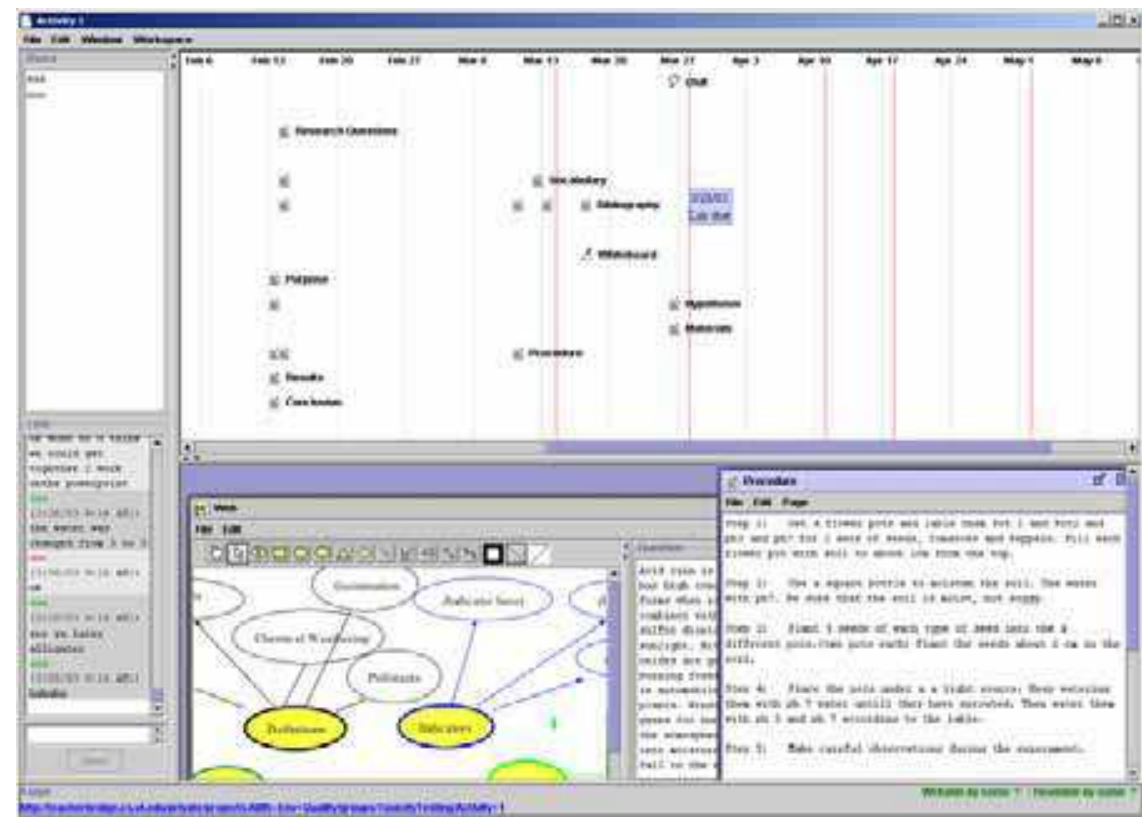

Fig. 3. Desktop client. Time is represented left to right, scrollable from the start to the end of the project. Icons represent work artefacts with each row containing the history of an individual item (A), the rightmost is thus the current version (B), with archived versions to the left (C), and darker vertical lines represent deadlines (D) (Ganoe et al., 2003). 
There are four large groups of graphic editors which are currently being used on the Net: tools that allow us to represent the visual structure of a set through organization charts (SmartDraw), tools that allow us to create mind maps or idea maps (FreeMind), those that allow us to build conceptual maps (LifeMap) and tools that permit the visual management of e-learning contents and/or organizers of the VLE contents.

The greatest strength of this set of visual tools is that they oblige the individual to make explicit what is apparently incomprehensible information (Coll \& Monereo, 2008).

Classroom BRIDGE, described in (Ganoe et al., 2003), and shown in Fig. 3, distributed group projects among school classrooms that might collaborate as part of a larger team including similar groups from other classrooms. The timelines present an integrated display of activity information on both the desktop and large screen displays. The information displayed is generated incidentally through automatic versioning and calendaring tasks.

Another visualization technique project is ENCCON, depicted in Fig. 4, which uses rectangles for the area division, rather than the polygons used in the Space-Optimized tree. ENCCON is used to represent the structure of collaborative workspace and logical relationships among the objects (e.g. learning elements), where nodes represent the objects (i.e. activities, artifacts, groups, events, agents, profiles, etc), while edges are used to present relationships among the objects, in this case is restricted to relational hierarchies (Nguyen et al., 2004).

Dicheva et al. (2005), with TM4L, make use of ontologies and propose the display of thematic maps of Learning Object collections with the support of semantic information, in addition to their interactive administration.

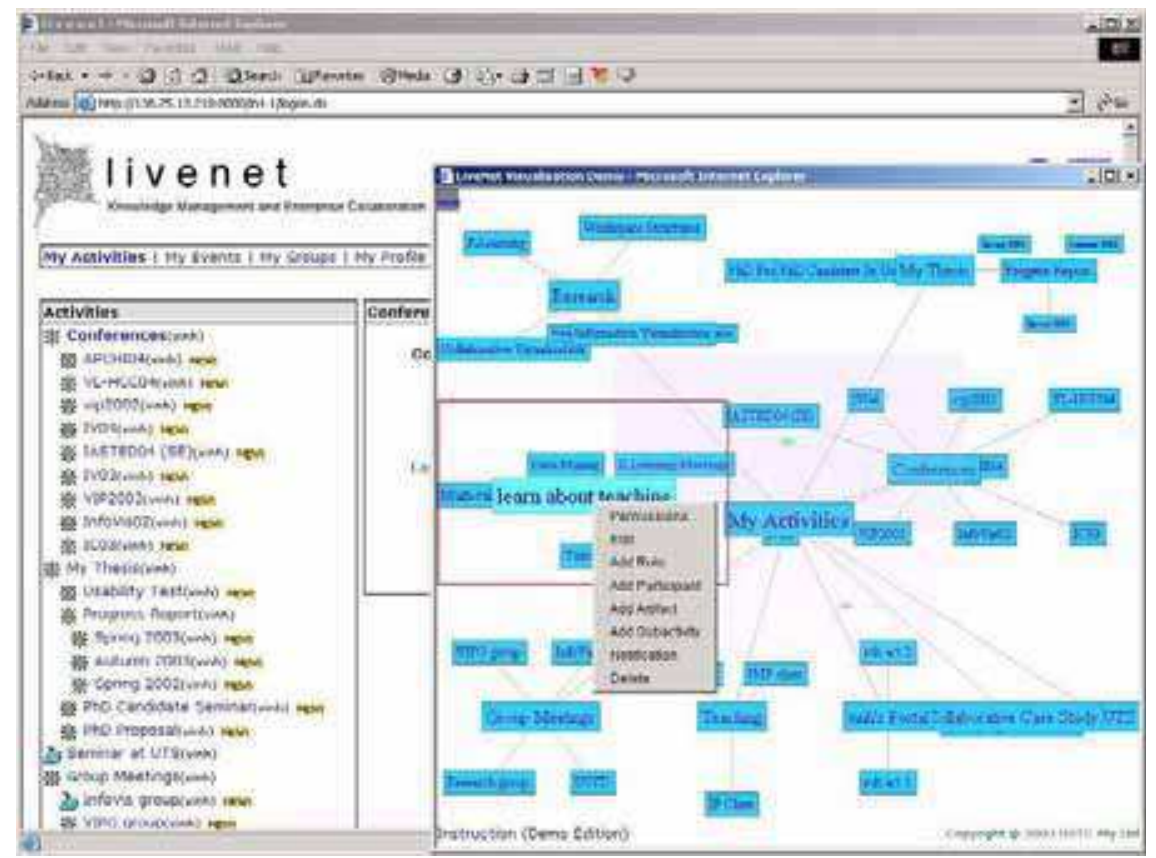

Fig. 4. An example of an operation menu popping up over a particular node which shows all actions, properties and associated attributes of the corresponding object (Ganoe et al., 2003). 
Finally, to solve the problem of expressing the same topic in different ways, this means that semantically identical concepts may be expressed by different terms from the domain vocabulary. In their study, (Guo \& Chen, 2006) integrate a domain lexicon in the ontology and thus define mappings from terms of the domain vocabulary to their meaning as defined by the concepts of the ontology; they thus present the learning material in various learning or presentation contexts, enabling access to particular learning material (see Fig. 5).

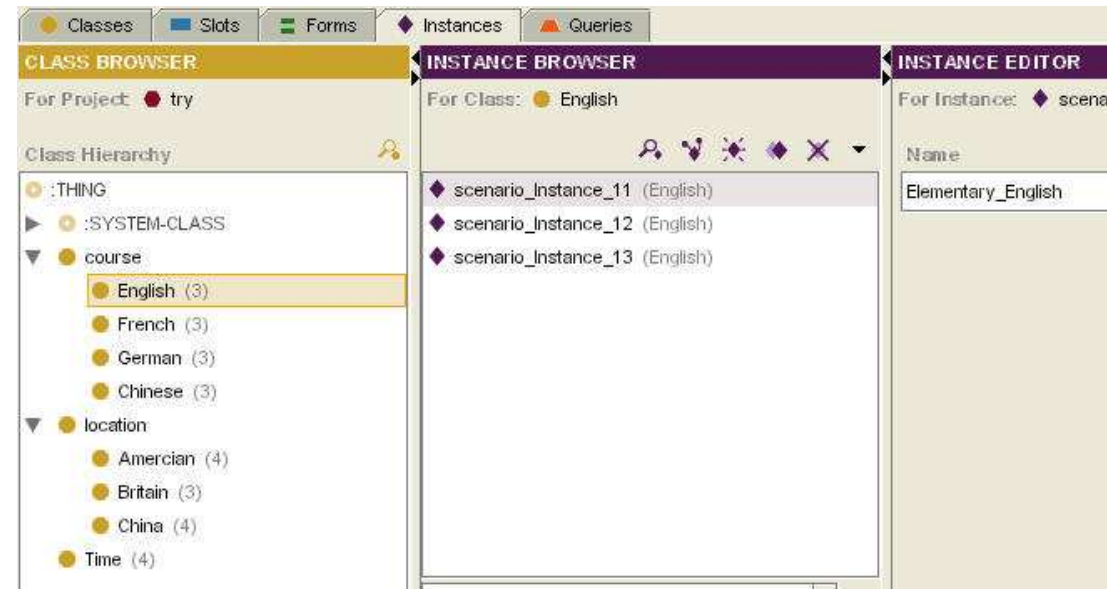

Fig. 5. Ontology Design and Representation for our E-Learning scenario (Guo \& Chen, 2006).

\subsection{Visual representation of the learning process to obtain useful new knowledge}

In addition to the visual representation of learning content with Learning Objects (LO), and the use of techniques to maximize learning through a series of Graphic Organizers (GO), it should not be forgotten that a student in virtual education is acting in a virtual learning environment that demands both the possibility and the necessity of representing the interaction dynamics of the learning process, which are barely visible in the organic form. Unlike traditional face to face education, all the actions or interventions taken by individuals can be reused and represented on the same platform and they remain registered in the data base, and it is necessary (because the learning in these virtual environments borrows from other types of visual helps - besides those of LO and GO) to understand the relationships woven among the individuals involved, such as recognizing respective actions in the platform and improving the learning and teaching strategies.

In other words, a technical possibility exists together with a pedagogical purpose, to offer a series of aids that allow whoever is learning with and in an LMS to represent the form in which the learning processes are being built. Therefore, a visual representation of the process, as a mediation instrument, can improve students' learning ability by allowing them to visualize the interaction taking place during the virtual education process.

Virtual learning environments, as educational spaces, offer a series of possibilities of social interaction, teacher-student or between students, through different synchronous or asynchronous channels. They also offer possibilities of interaction with a series of different educational materials, but do not give an image or overall representation of what happens in these spaces. For anyone operating in these educational spaces, it is of crucial importance 
to locate their action in the educational environment and recognize all the interactions that take place in the virtual training.

This has given rise to the tendency to use visual representations of everything that happens in the virtual learning environments, which is the same process, as a tool both for anyone who wants to understand and act within this space (either when they are learning individually or cooperatively), and for anyone who wants to understand and help as a tutor, as well as for those who want to improve operatively and enrich their teaching in an LMS. Because of this a tool has been created for both learners and teachers who work individually and cooperatively in a virtual learning environment.

Within this tendency we can highlight the Social Network Analysis (SNA) as a useful alternative for analyzing the social structures that emerge from the relationships among different social actors, used often in social psychology, anthropology, communication and politics. The SNA, as a set of analysis techniques for the formal study of the relationships among actors and for analyzing the social structures that emerge from these relationships, was founded in graphing theory to represent the behavior of webs. The web nodes can represent individuals, organizations, events or nations, whereas the arcs would correspond to the addresses, frequencies and strong points of the relationships between the nodes (Scott, 2000).

These visualization techniques are also beginning to be validated in online courses and there is a trend which shows that the SNA metrics and the visualizations of the interactions are potentially effective tools for analyzing patterns of interaction in virtual environments, for example in asynchronous virtual forums (Willging, 2008) in virtual education.

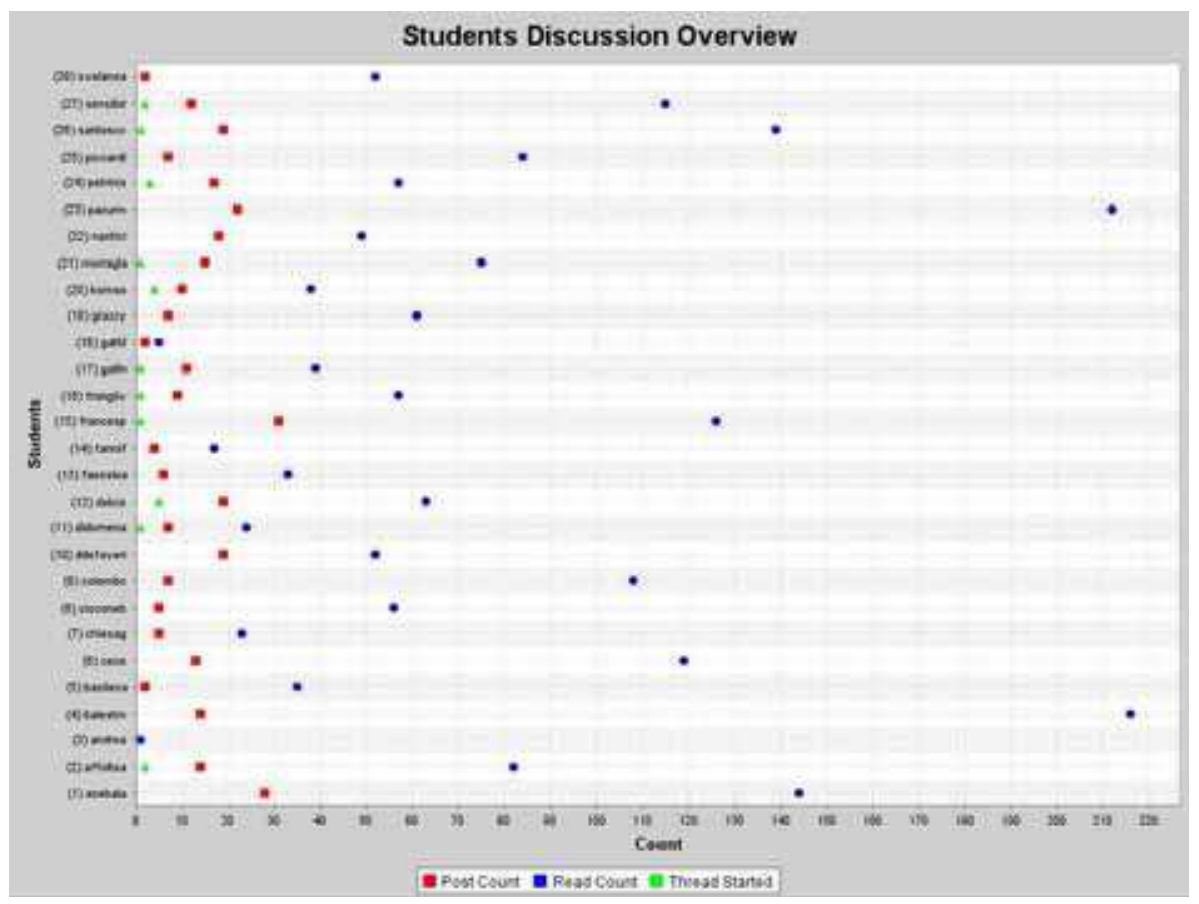

Fig. 6. Representation of the discussions (Mazza \& Milani, 2004). 
Nevertheless, if it is true that this type of analysis offers a visual representation of the social web interaction, it "begins by paying special attention to the study of the social structures, thus insisting less on why people do what they do and more on the comprehension of the structural conditions of their actions." (Sanz, 2003) That is, the SNA is focused on recognizing the patterns and relationships of the social structure that is woven in a social relationship.

As far as Visual Analytics is concerned, in addition to allowing a visualization of the relationships of the SNA type, it also seeks to reuse the information, not only by taking reticulated photographs of the web to understand its structure, but by trying to convert the information of the interaction into new useful and relevant knowledge for whoever learns, teaches, designs and researches in virtual learning environments.

\section{Summary of student's behaviours from 2002-01-15 to 2002-04-11 \\ Student: "francesco"}

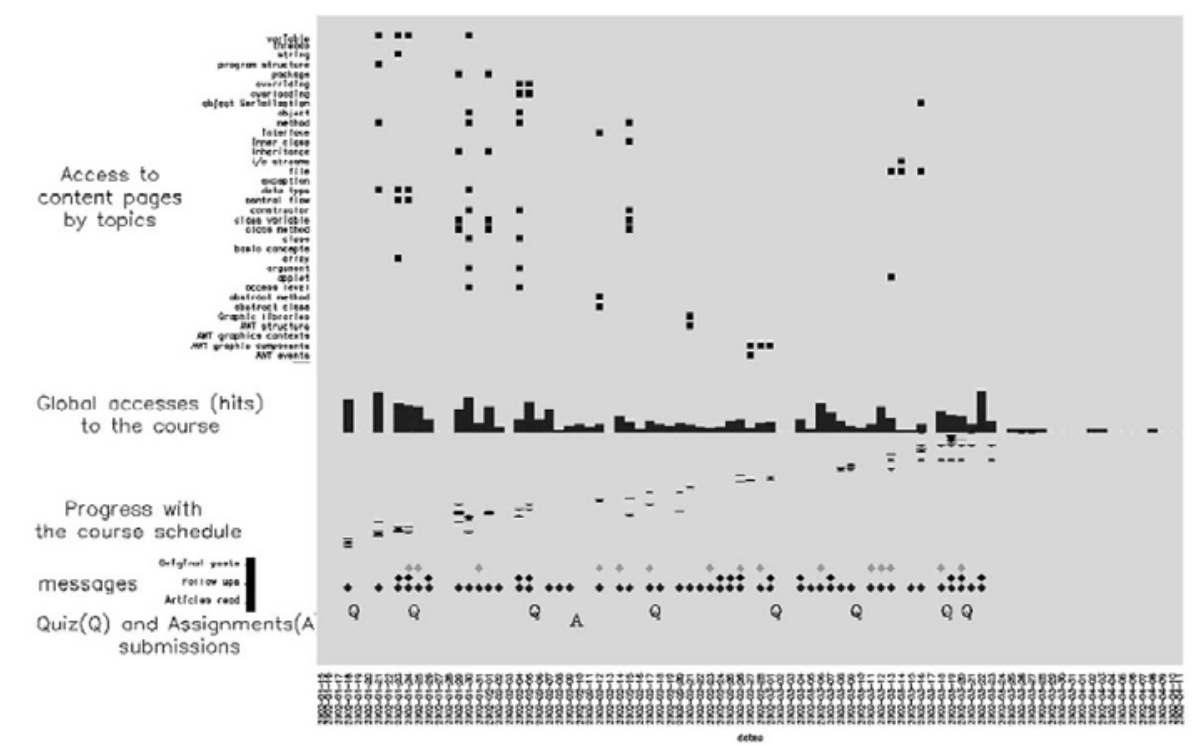

Fig. 7. The Behaviour Graph represents the student's behaviour (Mazza \& Dimitrova, 2005).

Each message has a sender, date, and topic. A set of posts on the discussion topic, comprised of an initial post and all its responses, is called a thread. The person who sends the initial message in a thread is called the originator. Mazza and Milani (2004) showed the instant at which users enter the platform and a representation of the frequency of reading and writing in the fora, as well as the thread originator. Furthermore, they represent the students' accesses to a particular resource of the course. Fig. 6 shows data on discussions throughout the course described in Mazza and Milani's article. In this chart the instructors have an overview of all the discussions carried out by students. For each student of the course it gives indications of the number of messages posted (with a square), number of messages 
read (with a circle) and finally the number of threads started by the student in the discussions (with a triangle).

In CMS the visits and posts over time for each person are stored. In (Hardless \& Nulden, 1999) they try to help with the blindness of tutors in the asynchronous nature of the learning activities when the electronic environment leaves some of the individuals involved without a complete picture of the activities, progress and usage patterns.

A tool called CourseVis presented in (Mazza \& Dimitrova, 2005) generates several graphic representations in $3 \mathrm{D}$ and $2 \mathrm{D}$, classified according to social, cognitive and behavioral aspects. Its aim is to help the instructors to form a mental model of their classes in order to be able to offer students the appropriate help, suggesting a scatter-plot-based representation of the online discussions and a matrix to visualize the students' performance on quizzes related to domain concepts.

Illustrated in Fig. 7 of Mazza \& Dimitrova's study is the information regarding a particular student. It takes advantage of the single-axis composition method (Mackinlay, 1986) to present a large number of variables in a $2 \mathrm{D}$ metric space. With a common $\mathrm{x}$-axis mapping the dates of the course, a number of variables are represented: accesses to content pages by topics, total accesses to the course, progress with the course schedule, messages and quiz and assignment submission.

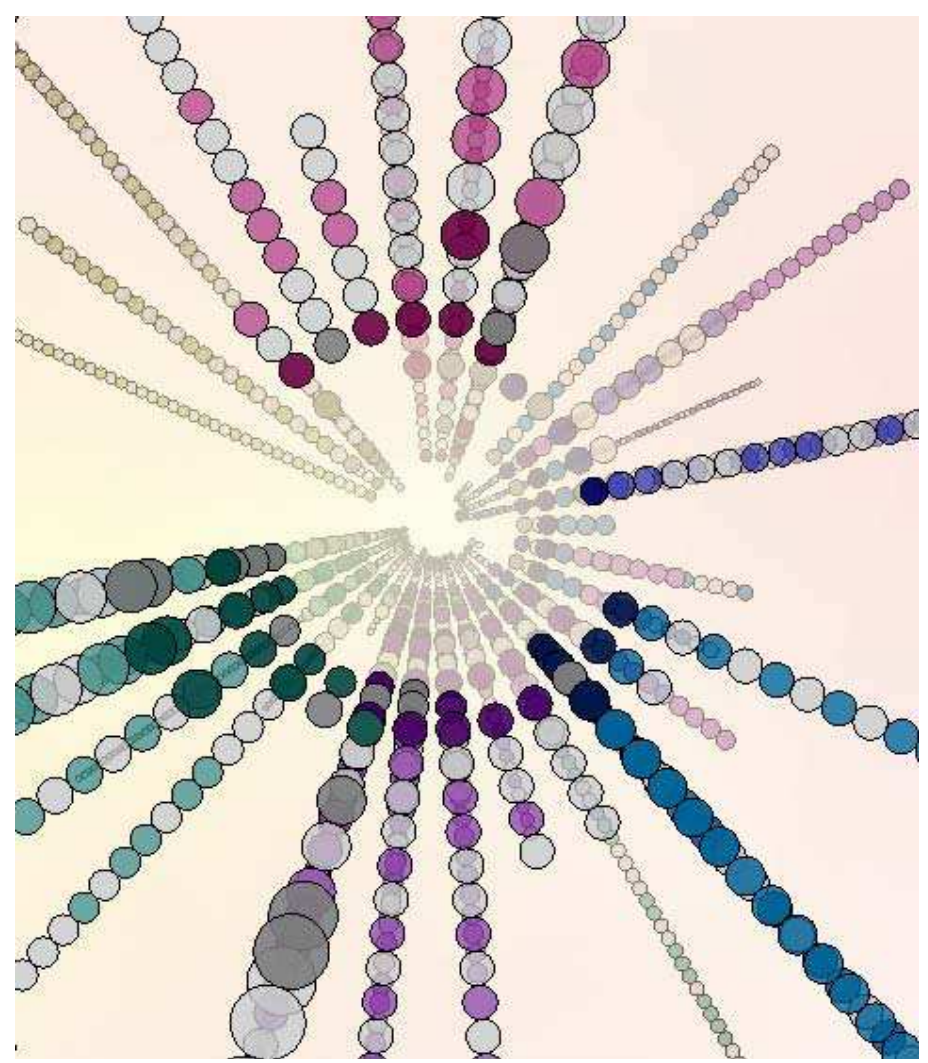

Fig. 8. Top view of CrystalChat (Tat \& Carpendale, 2006). 
In (Donath, 2002), three such projects are discussed: Coterie, PeopleGarden, and the Loom Project. The first one highlights two key elements: the activity of the participants and the structure of the conversation. Second, PeopleGarden uses a flower and garden metaphor to visualize participation on a message board. Finally, the Loom Project's goal is to create evocative, semantically based visualizations of Usenet newsgroups.

Gibbs et al. (2006) present the mapping of the temporal relations of discussions on software (MTRDS) aimed at helping to analyze the temporal aspects of online educational course discussions, highlighting important information related to interaction patterns. Likewise, CrystalChat (Tat \& Carpendale, 2006), using 3D switchable to 2D visual representation, reveals the patterns in an individual's communications with those people who are part of their personal chat history.

As shown in Fig. 8, each facet is composed of a series of conversations which are constructed as follows: a colored disc represents a single message and each color indicates a different person, a left to right reading sequencing is used to order these messages (that is, the messages are arranged so that the first message in the conversation starts on the left), a conversation is defined, as in the data, by the opening and closing of the chat window, where one row of message discs represents a conversation.

For a review of the search patterns in the interaction of learning networks, see (Laat et al., 2007), which represents how balanced the participation is within the learning community.

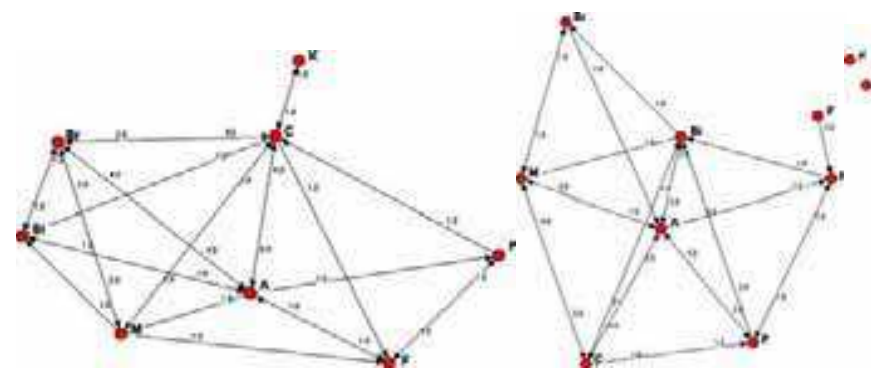

a) Beginning phase.

b) Middle phase.

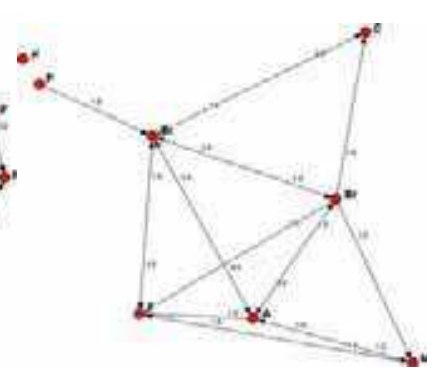

c) End phase.

Fig. 9. Interaction patterns among eight participants in different phases of a learning task (Laat et al., 2007).

Laat et al. show (Fig. 9) and discuss participatory pattern changes over time. To understand the complex dynamics of Network Learning / Computer-Supported Collaborative Learning, it is important to use methods that help us to see the 'patterns' of interactions between the participants and their temporal dynamics. 


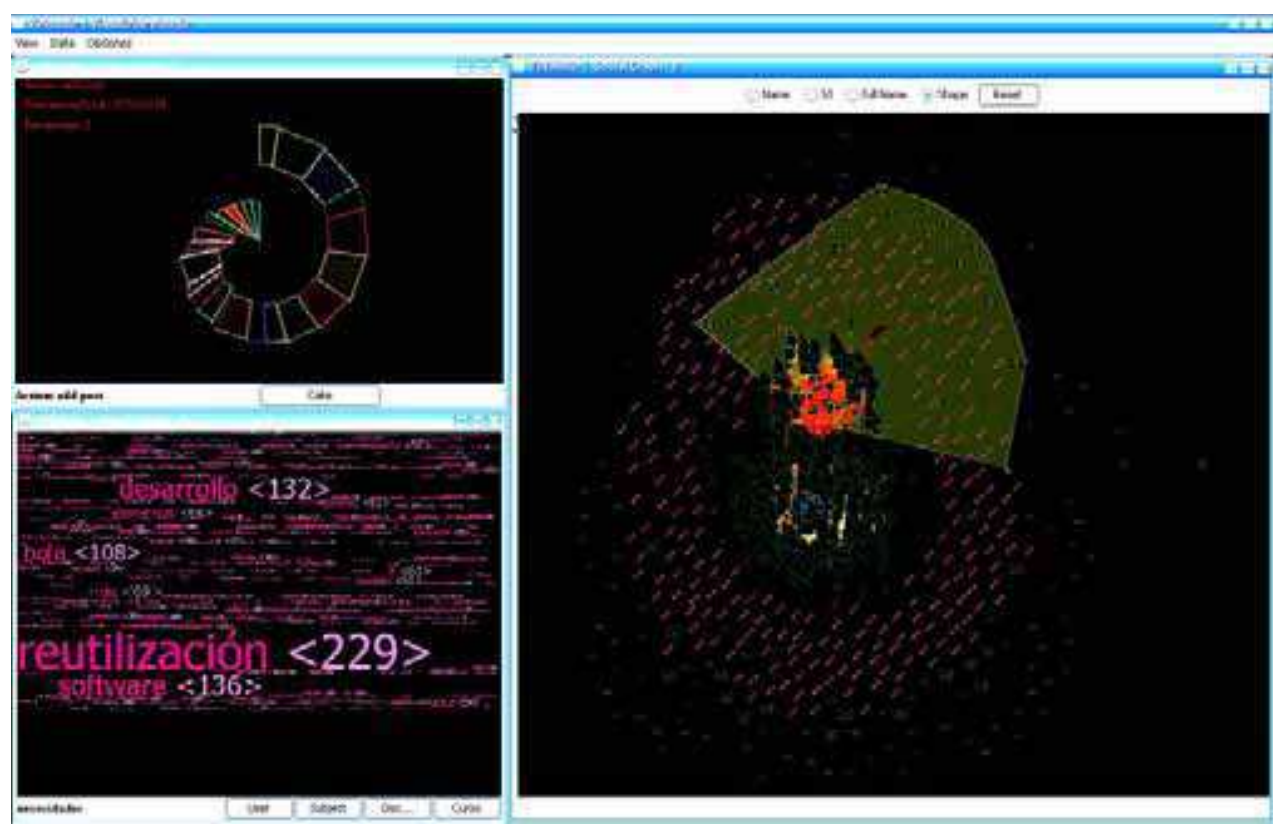

Fig. 10. Overall visualization of relationships among users (Gómez Aguilar et al., 2008).

This research (Gómez Aguilar et al., 2008) proposes interactive visualizations of the social networks that are formed among the participants around an activity on the educational online platform; moreover, a tag cloud shows the most relevant words that can be viewed among the keywords, the users, the courses, the discussions and the subjects of forum posts, obtained from the analysis of all the semantic content and information exchanged in the platform. In addition, the different roles that they may be playing are exhibited, as is their use of technological tools, and finally how their own particular behavior affects their learning (see Fig. 10).

(Gómez Aguilar et al., 2009) propose and develop innovative interactive visual solutions to help different users of e-learning platforms extract specific knowledge related to the complex process of education and learning. In that study they were particularly interested in the evolution of the learning process as well as in how and when people were involved in it.

The general idea behind spiral distortion is the following: instead of having a regular spiral shape, with a constant increase in radius, the distance from the centre to the next bar to be drawn depends on the height of the previous bars on the same angle. Put into a simple metaphor: the evolution of the spiral is quite similar to that of tree-rings. In Fig. 11 we can see a spiral representation where each spin spiral (360 degrees) represents a week, and seven sectors represent each of the days of the week. This option highlights the fact that three days (Thursday, Friday and Saturday) contain the largest accumulation of activities, with Thursday being the day with the highest concentration. 


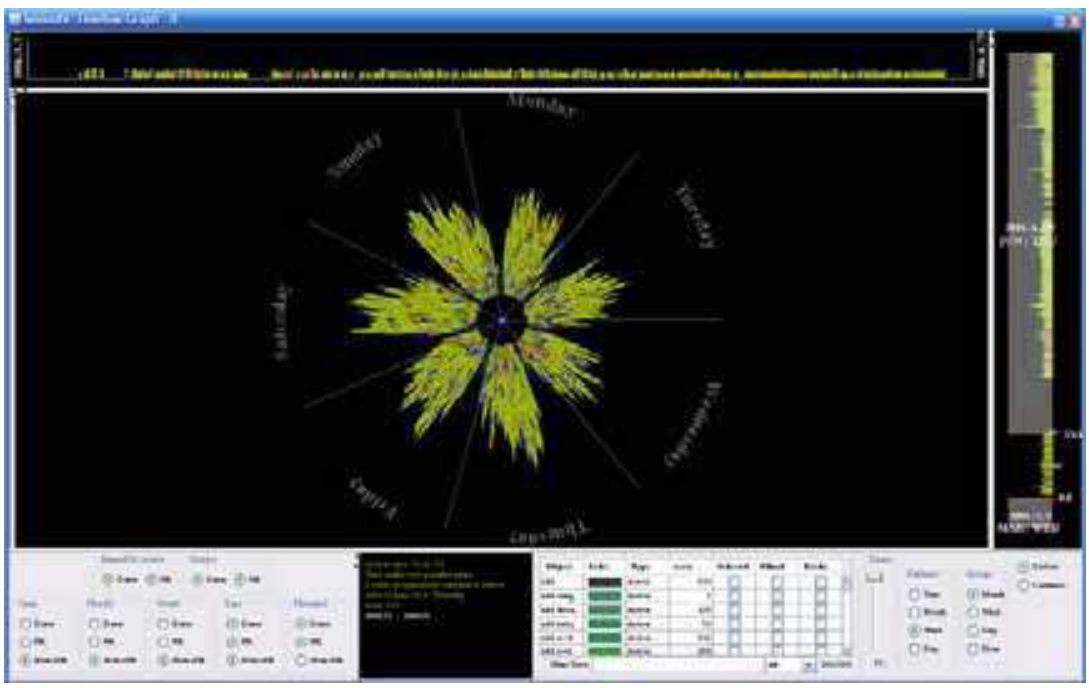

Fig. 11. Weekly pattern for the chosen course (Gómez Aguilar et al., 2009).

Based on the idea of constructivist learning, where the exchange of information and feedback from it are the basis for the creation of new knowledge, we present the results of the evaluation of the HEODAR tool mentioned and explained above as a mechanism to contribute new information about the assessment of learning objects, thus providing important information for both tutors and students (E. M. Morales Morgado, 2009). Fig. 12 shows that the representation uses a 5-star rating from 1 to 5 , filled in depending on the case, either by values or weighted values. The LO assessment, as shown in Fig. 12, is divided into three parts: 1 is the representation of the average of the results of all assessments made of the LO (this is the LO assessment); 2 represents the value multiplied by the percentage of teachers who have evaluated the $\mathrm{LO}$ with respect to the total number of teachers, resulting in the weighted assessment, and finally, 3 is the percentage of teachers who have evaluated the $\mathrm{LO}$ with respect to the total number of teachers.

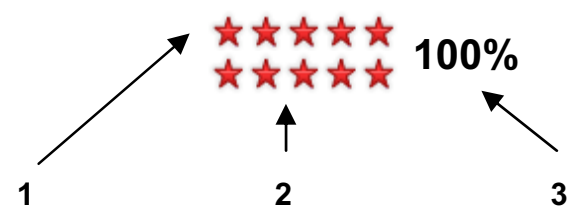

Fig. 12. HEODAR representation (E. M. Morales Morgado, 2009).

Finally, a work closely related to the present article is (Williams \& Conlan, 2007), in which they present a prototype narrative analyzer, which displays the correlation between learner activity and the adaptive e-Learning course, displaying narrative structures and the learning style of students in the systems of e-learning and also the use of a simple timeline for selecting the narrative structures. The narrative analyzer display, see Fig. 13, is divided into four visually separate areas. These are: the display parameter settings menus, the narrative 
display, the learning style display, and the timeline display area. Each area has unique properties when different narrative or learner display options are selected. The display parameter setting area consists of a number of pull down menus, which allow selection of learners and narrative display types, as well as options for the display of subsection names when displaying access log narratives. The narrative display area is where the various permutations of the course and access log file based narrative structures are displayed. Narratives are drawn from the top left corner of the display area and extend by the width of one narrative subsection block to the right for each course narrative event or log file access narrative event.

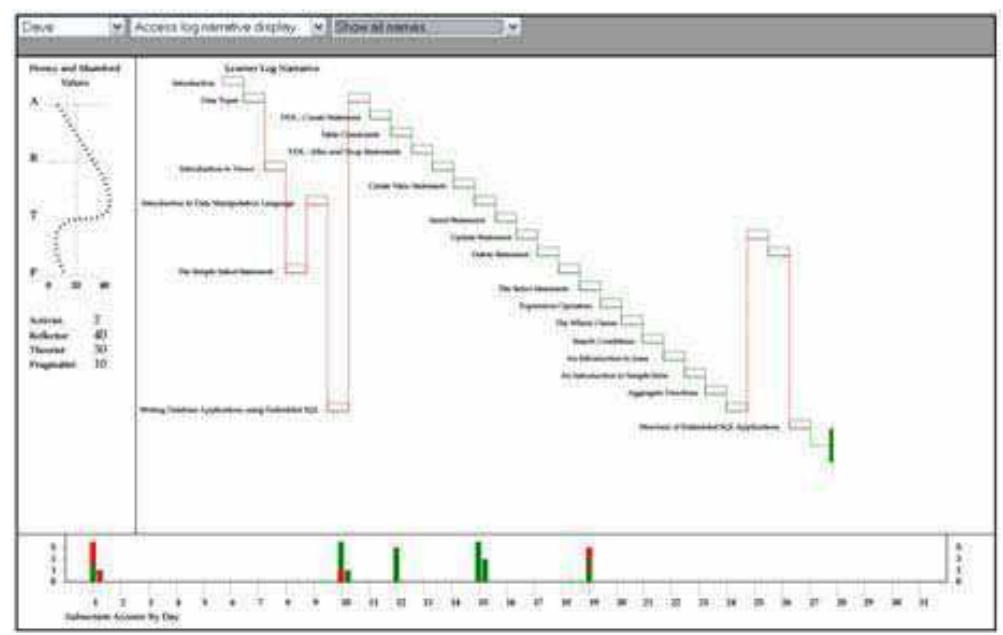

Fig. 13. The prototype narrative analyzer (Williams \& Conlan, 2007).

\section{Summary and conclusions}

It is more than evident that the use of visual representations to analyze, represent and organize the content of VLE to support e-learning is a complementary contribution and a useful part of the learning process. As we can see, the use the visual representations to support e-learning is growing at the same rate as their complex and innovative design. Moreover, it should be noted that each investigation mentioned the use of different VLE or e-learning platforms. Therefore it is important to point out that not only is usability important in visualizations, but also the standardization and creation of visual interactive representations that can be used independently of the VLE and / or be embedded in the platforms. In (Scholtz, 2006), we can find five areas or aspects of visual analytic environments that should be considered as metrics and methodologies for evaluations to be developed. Evaluation aspects need to include usability, but it is necessary to go beyond basic usability. To summarize, the goal of visualization researchers is to produce visual representations of complex relationships that help users to focus their attention efficiently. In the specific case of e-learning, this can be done through the visual interactive analysis of:

- a user's recorded activities, stored in their e-learning platforms, which can provide a means to understand students' behavior and learning processes throughout their learning period. 
- the semantic content uploaded in the e-learning platforms as well as the plain text and Learning Objects (LO) in it, which can bring out the general view of a course, theme or whole platform, and can also be a kind of shortcut to the specific content, course, or LO.

- social relations that are commonly hidden but can be extremely useful to understand the grouping of users in the learning process.

With the objective of supplying feedback to e-learning, the result of applying visual analytics in the interaction processes in LMS consists of:

- Analyzing a visual report of the participants' activity flow and distribution (students, teachers, administrators, guests, etc.) in the virtual platform.

-Having elements of constant empirical judgment to improve the design of the interaction organization, as well as the design and management of the virtual platform.

- Facilitating for the teachers the precise identification of the different students' learning needs and therefore the opportunity to intervene.

- Reutilizing the information to adjust student learning strategies or the teaching focus.

Another important aspect to mention is the escalating attempts of individuals to adapt or support traditional education with e-learning. Accordingly, there is a continuous drive to store and organize the content of VLE. Therefore, it is important not to lose sight of the creation and development of standards of intuitive visual tools that permit the analysis and management of this semantic content. Finally it is important to mention that many other forms exist for representing the information and techniques for interacting with it. These visualization and interaction techniques should be tested for their usefulness and effectiveness in e-learning. Examples of customary ways of representing a timeline abound in the literature as does the use of a linear arrangement (using Cartesian coordinates) with time represented on the x-axis. Following this approach, and in an attempt to solve the problem that representing extensive timelines poses, (Dachselt \& Weiland, 2006) proposed a bifocal deformation, whereas (André et al., 2007) suggested a visual filter in the timeline for the data that will be represented in detail. Although seen much less commonly, time may also be represented on a spiral. (Carlis \& Konstan, 1998) explore this in both 2D and 3D. Similar work can be found in (Weber et al., 2001), but in this case the spiral itself serves as a filter for 3D data. In (Bergstrom \& Karahalios, 2007), this concept is applied to a much more restricted dataset, as is the case of a single conversation. Apart from examining the representation of timelines, the modes of interaction with the user have also been the object of study. (Koike et al., 1997) proposed an efficient slider and a temporal window that serves as a filter. In addition, (Daassi et al., 2006) reviewed the different techniques of temporal visualization available and classified them. Finally, another work by (Aigner et al., 2007) has reviewed different ways of displaying temporary data according to the features each one offers.

\section{Acknowledgments}

This work was partially supported by the Ministerio de Educación y Ciencia (project GRACCIE (CONSOLIDER-INGENIO, CSD 2007- 00067)) and by the Junta de Castilla y León (projects GR47 and GR34). 


\section{References}

Aigner, W.; Miksch, S.; Müller, W.; Schumann, H.; \& Tominski, C. (2007). Visualizing timeoriented data-A systematic view. Comput. Graph., 31(3), 401-409.

André, P.; Wilson, M.L.; Russell, A.; Smith, D.A.; Owens, A.; \& M.C, s. (2007). Continuum: designing timelines for hierarchies, relationships and scale. Proceedings of UIST '07: Proceedings of the 20th annual ACM symposium on User interface software and technology, New York, NY, USA.

Ariyasu, K.; Yamada, I.; Sumiyoshi, H.; Shibata, M.; \& Yagi, N. (2005). Visualization of TextBased Dialog in a Virtual Classroom for e-Learning. IEICE - Trans. Inf. Syst., E88$D(5), 836-842$.

Ausubel, D.; Novak, J.; \& Hanesian, H. (1983). Psicología Educativa. Un punto de vista cognoscitivo (2 ed. Vol. 18), Trillas, México.

Bergstrom, T.; \& Karahalios, K. (2007). Conversation Clock: Visualizing audio patterns in colocated groups. Proceedings of the 40th Hawaii International Conference on System Sciences - 2007, 78c.

Bruner, J. (1999). La educación, puerta de la cultura. Madrid, Visor.

Butcher, K.R.; \& Kintsch, W. (2004). Learning with Diagrams: Effects on Inferences and the Integration of Information. In: Diagrammatic Representation and Inference, S. B. Heidelberg (Ed.), (Vol. 2980/2004, pp. 337-340).

Carlis, J.V.; \& Konstan, J.A. (1998). Interactive visualization of serial periodic data. Proceedings of UIST 198: Proceedings of the 11th annual ACM symposium on User interface software and technology, New York, NY, USA.

Castaño, C. (2004). Utilización de mapas conceptuales para la construcción de modelos de conocimiento. Comunicación y Pedagogía: Nuevas tecnologías y recursos didácticos, 194, 75-79.

Cogliati, J.J.; Goosey, F.W.; Grinder, M.T.; Pascoe, B.A.; Ross, R.J.; \& Williams, C.J. (2005). Realizing the promise of visualization in the theory of computing. J. Educ. Resour. Comput., 5(2), 5 .

Coll, C.; \& Monereo, C. (2008). Psicología de la educación virtual. Aprender y enseñar con las tecnologías de la Información y la Comunicación., Morata, Madrid.

Chiappe, A.; Segovia, Y.; \& Rincón, H. (2007). Toward an instructional design model based on learning objects. Educational Technology Research and Development, 55, 671-681.

Chudá, D. (2007). Visualization in education of theoretical computer science. Proceedings of CompSysTech '07: Proceedings of the 2007 international conference on Computer systems and technologies, New York, NY, USA.

Daassi, C.; Nigay, L.; \& Fauvet, M.C. (2006). A taxonomy of temporal data visualization techniques. Revue Information-Interaction-Intelligence, Revue en Sciences du Traitement de l'Information (A journal in the Sciences of Information Engineering) Vol. 5, No 2, 4163.

Dachselt, R.; \& Weiland, M. (2006). TimeZoom: a flexible detail and context timeline.

Proceedings of $\mathrm{CHI}$ '06: $\mathrm{CHI}$ ' 06 extended abstracts on Human factors in computing systems, New York, NY, USA.

Dicheva, D.; Dichev, C.; \& Wang, D. (2005). Visualizing topic maps for e-learning. Fifth IEEE International Conference on Advanced Learning Technologies. ICALT 2005, 6, 950-951

Donath, J. (2002). A semantic approach to visualizing online conversations. Commun. ACM, $45(4), 45-49$. 
E. M. Morales Morgado, D.A.G.A.F.J.G.P.R.T.S. (2009). Supporting the Quality of Learning Objects Through Their Ranking Visualization. International Journal of Emerging Technologies in Learning (iJET), 4, 24-29.

Ewy, C. (2003). Teaching With Visual Frameworks: Focused Learning and Achievement Through Instructional Graphics Co-Created by Students and Teachers, CA, Corwin Press.

Ganoe, C.H.; Somervell, J.P.; Neale, D.C.; Isenhour, P.L.; Carroll, J.M.; Rosson, M.B., et al. (2003). Classroom BRIDGE: using collaborative public and desktop timelines to support activity awareness. Proceedings of UIST '03: Proceedings of the 16th annual ACM symposium on User interface software and technology, New York, NY, USA.

Gibbs, W.J.; Olexa, V.; \& Bernas, R.S. (2006). A Visualization Tool for Managing and Studying Online Communications. 9 232--243

Gómez Aguilar, D.A.; Therón, R.; \& García Peñalvo, F.J. (2008). Understanding educational relationships in Moodle with ViMoodle. Advanced Learning Technologies, 2008. ICALT 2008. 8th IEEE International Conference on, 6, 954-956

Gómez Aguilar, D.A.; Therón, R.; \& García Peñalvo, F.J. (2009). Semantic spiral timelines used as support for e-learning. Journal of Universal Computer Science (j-jucs). 15: 7. 1526-1545

Granda, J.C.; Uria, C.; Garcia, D.F.; Suarez, F.J.; \& Gonzalez, F. (2008). Design Issues in Remote Visualization of Information in Interactive Multimedia E Learning Systems. Proceedings.

Guo, W.; \& Chen, D. (2006). Semantic Approach for e-learning System. Computer and Computational Sciences, 2006. IMSCCS '06. First International Multi-Symposiums on, 2 $442-446$

Hardless, C.; \& Nulden, U. (1999). Visualizing Learning Activities to Support Tutors. 312313.

Koike, Y.; Sugiura, A.; \& Koseki, Y. (1997). TimeSlider: an interface to specify time point. Proceedings, New York, NY, USA.

Laat, M.; Lally, V.; Lipponen, L.; \& Simons, R.-J. (2007). Investigating patterns of interaction in networked learning and computer-supported collaborative learning: A role for Social Network Analysis. International Journal of Computer-Supported Collaborative Learning, 2(1), 87 - 103.

Mackinlay, J. (1986). Automating the design of graphical presentations of relational information. ACM Trans. Graph., 5(2), 110--141.

Mazza, R.; \& Dimitrova, V. (2005). Generation of graphical representations of student tracking data in course management systems. Information Visualisation, 2005. Proceedings. Ninth International Conference on, 253-258.

Mazza, R.; \& Milani, C. (2004). GISMO: a Graphical Interactive Student Monitoring Tool for Course Management Systems. 18-19.

McCormick, B.H.; DeFanti, T.A.; \& Brown, M.D. (1987). Definition of visualization. SIGGRAPH Comput. Graph., 21(6), November 1987, 3-3

Muller, W.; \& Schumann, H. (2003, December). Visualization methods for time-dependent data - an overview. Proceedings.

Nguyen, Q.V.; Huang, M.L.; \& I, H. (2004). A new visualization approach for supporting knowledge management and collaboration in e-learning Quang Vinh Nguyen. Information Visualisation, 2004. IV 2004. Proceedings. Eighth International Conference on, 693 - 700 . 
Ploetzner, R.; \& Lowe, R. (2004). Dynamic visualisations and learning. Learning and Instruction, 14 235-240.

Prendes Espinosa, M.P. (1994). La imagen didáctica: Análisis descriptivo y evaluativo, Universidad de Murcia, Facultad de Educación.

Robling, G.; Naps, T.; Hall, M.S.; Karavirta, V.; Kerren, A.; Leska, C., et al. (2006). Merging interactive visualizations with hypertextbooks and course management. 166-181.

Sangrà, A. (2008). Los materiales de aprendizaje en contextos educativos virtuales, Universitat Oberta de Catalunya (UOC), Barcelona, Esp.

Sanz, L. (2003). Análisis de Redes Sociales: O cómo representar las estructuras sociales subyacentes. Apuntes de Ciencia y Tecnología, 7.

Scott, J. (2000). Social Network Analysis: A Handbook (2 ed.), Sage Publications., London.

Schnotz, W. (2002). Multimedia Learning from a cognitive Perspective, Seminario sobre utilización de las TIC en educación superior. (Vol. Un enfoque crítico). Madrid, España: Universidad Autónoma de Madrid.

Scholtz, J. (2006). Beyond Usability: Evaluation Aspects of Visual Analytic Environments. Visual Analytics Science And Technology, 2006 IEEE Symposium On, 145-150.

Schweitzer, D.; \& Brown, W. (2007). Interactive visualization for the active learning classroom. Proceedings of SIGCSE '07: Proceedings of the 38th SIGCSE technical symposium on Computer science education, New York, NY, USA.

Shneiderman, B. (1996, September). The eyes have it: a task by data type taxonomy for information visualizations. Proceedings of IEEE Symposium on Visual Languages.

Software, I. (2003). Graphic Organizers: A Review of Scientifically Based Research. The Institute for the Advancement of Research in Education (IARE).

Suárez, C. (2008). Educación y virtualidad. Bases para el aprendizaje cooperativo en red, Universidad Ricardo Palma, Lima.

Tat, A.; \& Carpendale, S. (2006). CrystalChat: Visualizing Personal Chat History. Proceedings of International Conference on System Sciences, 2006. HICSS '06., Hawaii

Thomas, J.J.; \& Cook, K.A. (2005). Illuminating the Path: The Research and Development Agenda for Visual Analytics, National Visualization and Analytics Ctr.

Thomas, J.J.; \& Cook, K.A. (2006). A visual analytics agenda. Computer Graphics and Applications, IEEE, $26 \% 6(1), 10-13 \% \&$.

Villalba Simón, M.R.; Martínez Liébana, I.; Checa Benito, F.J.; Robles, M.M.; Martín Andrade, P.; Nuñez Blanco, M.Á., et al. (2000). Aspectos evolutivos y educativos de la deficiencia visual (Vol. 1), Organización Nacional de Ciegos Españoles (ONCE). Dirección de Educación.

Vygotskii, L.S. (Ed.). (2000). El desarrollo de los procesos psicológicos superiores (1 ed.). Barcelona: Crítica.

Weber, M.; Alexa, M.; \& Müller, W. (2001). Visualizing Time-Series on Spirals. IEEE Symposium on Information Visualization, 2001. INFOVIS 2001., 7

Willging, P. (2008). Técnicas para el análisis y visualización de interacciones en ambientes virtuales. Revista hispana para el análisis de redes sociales, 14(6).

Williams, F.P.; \& Conlan, O. (2007). Visualizing Narrative Structures and Learning Style Information in Personalized e-Learning Systems. Seventh IEEE International Conference on Advanced Learning Technologies, 2007. ICALT 2007., 7, 872-876. 


\section{Advances in}

Learning Processes

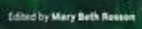

\section{Advances in Learning Processes}

Edited by Mary Beth Rosson

ISBN 978-953-7619-56-5

Hard cover, 284 pages

Publisher InTech

Published online 01, January, 2010

Published in print edition January, 2010

Readers will find several papers that address high-level issues in the use of technology in education, for example architecture and design frameworks for building online education materials or tools. Several other chapters report novel approaches to intelligent tutors or adaptive systems in educational settings. A number of chapters consider many roles for social computing in education, from simple computer-mediated communication support to more extensive community-building frameworks and tools. Finally, several chapters report state-of-the-art results in tools that can be used to assist educators in critical tasks such as content presentation and grading.

\section{How to reference}

In order to correctly reference this scholarly work, feel free to copy and paste the following:

Diego Alonso Gomez Aguilar, Cristobal Suarez Guerrero, Roberto Theron Sanchez and Francisco Garcia Penalvo (2010). Visual Analytics to Support E-learning, Advances in Learning Processes, Mary Beth Rosson (Ed.), ISBN: 978-953-7619-56-5, InTech, Available from: http://www.intechopen.com/books/advances-inlearning-processes/visual-analytics-to-support-e-learning

\section{INTECH}

open science | open minds

\section{InTech Europe}

University Campus STeP Ri

Slavka Krautzeka 83/A

51000 Rijeka, Croatia

Phone: +385 (51) 770447

Fax: +385 (51) 686166

www.intechopen.com

\section{InTech China}

Unit 405, Office Block, Hotel Equatorial Shanghai

No.65, Yan An Road (West), Shanghai, 200040, China

中国上海市延安西路65号上海国际贵都大饭店办公楼 405 单元

Phone: +86-21-62489820

Fax: +86-21-62489821 
(C) 2010 The Author(s). Licensee IntechOpen. This chapter is distributed under the terms of the Creative Commons Attribution-NonCommercial-ShareAlike-3.0 License, which permits use, distribution and reproduction for non-commercial purposes, provided the original is properly cited and derivative works building on this content are distributed under the same license. 